NAVAS, Iván. "Acción y omisión en la infracción de deberes negativos en derecho penal".

Polit. crim. Vol. 10, No 20 (Diciembre 2015), Art. 8, pp. 678-693.

[http://www.politicacriminal.cl/Vol_10/n_20/Vol10N20A8.pdf]

\title{
Acción y omisión en la infracción de deberes negativos en derecho penal
}

\section{Action and omission in the infringement of negative duties in penal law}

\author{
Iván Navas \\ Doctor en Derecho y Magister en Derecho \\ Penal y Ciencias Penales, Universidad Pompeu Fabra. \\ Profesor e investigador de Derecho Penal \\ Universidad San Sebastián \\ ivan.navas@uss.cl
}

\section{Resumen}

El trabajo presenta una propuesta de distinción entre deberes negativos y positivos como fundamento de la responsabilidad penal. Se centra en el estudio de los deberes negativos y las formas de su infracción distinguiendo la vulneración por acción y la vulneración por omisión del deber negativo. Pretende poner de manifiesto la necesidad de interpretar los tipos penales de la parte especial de acuerdo a existencia de deberes negativos (y positivos) más allá de la distinción entre prohibición y mandato.

Palabras clave: deberes negativos, responsabilidad penal, omisión, posición de garante.

\section{Zusammenfassung}

Der Beitrag stellt einen Vorschlag zur Unterscheidung zwischen negativen und positiven Pflichten als Grundlage der strafrechtlichen Verantwortung dar. Dabei konzentriert man sich auf die Untersuchung der negativen Pflichten und der Formen ihrer Verletzung, die ihrerseits zwischen "Verletzungen durch Handeln" und "Verletzungen durch Unterlassen" unterschieden werden. Diese Studie versucht ferner aufzuzeigen, dass die Interpretation der Tatbestände des Besonderen Teils in Anbetracht der Existenz von negativen und positiven Pflichten notwending ist und dass diese Aufgabe ohne Berücksichtigung der klassischen Unterscheidung zwischen "Verbot" und "Gebot" beim Verständnis der Norm erfüllt werden kann.

Stichworte: negative Pflichten, strafrechtliche Verantwortung, Unterlassung, Garantenstellung

\section{Abstract}

This article presents a proposal to make a distinction between negative and positive duties as basis of criminal liability. It focuses on the negative duties and the ways of its infringement distinguishing between the infringement by action and the infringement by 
NAVAS, Iván. “Acción y omisión en la infracción de deberes negativos en derecho penal".

omission the negative duty. The article aims to highlight the need to interpret the criminal norm that creates Substantive Offences (Special Part) according to the existence of negative duties (and positive duties) beyond the distinction between prohibitions and mandates.

Key words: negative duties, criminal liability, omission, guarantee position.

\section{Introducción.}

Armin Kaufmann sostenía que de toda norma emana una sola clase de deber: de las normas prohibitivas sólo deberes de omitir y de las normas de mandatos sólo deberes de obrar ${ }^{1}$. En un sentido similar, en la Teoría del Derecho se suele señalar que los deberes pueden ser positivos si consisten en hacer y negativos si consisten en no hacer algo ${ }^{2}$. En el derecho penal se distingue entre prohibición y mandato en relación a la norma que prohíbe una determinada acción y en relación a la norma que exige la ejecución de una acción bajo la amenaza de sanción respectivamente. Es decir, se sanciona tanto por la realización de la acción prohibida como por la omisión de la acción no realizada. De allí que se diferencia entre norma prohibitiva y norma de mandato o entre norma de prohibición para los delitos comisivos y norma de requerimiento para los delitos omisivos ${ }^{3}$. Bajo esta distinción entre prohibición y mandato y desde la aparición de los primeros trabajos del tema, en la doctrina chilena suele sostenerse que la sanción por ejemplo de la omisión propia viene dada por la infracción de un mandato de hacer ${ }^{4}$.

Ahora bien, en su estructura el delito puede ser visto en todo caso como la infracción de un

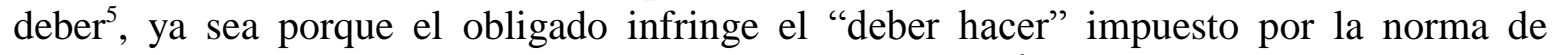
conducta al no cumplir con el comportamiento que ella fija ${ }^{6}$ o porque vulnera, por un lado,

\footnotetext{
${ }^{1}$ KAUFMANN, Armin, Dogmática de los delitos de omisión, Trad. CUELLO, Joaquín/SERRANO, José Luis, Madrid-Barcelona: Marcial Pons, 2006, p. 267. En el mismo sentido en la doctrina chilena COUSIÑO MACIVER, Luis, Derecho penal chileno, t. I, Santiago de Chile: Editorial Jurídica de Chile, 1975, p. 502. Debido al planteamiento que subyace en la construcción de Kaufmann, el problema de la omisión impropia consistía para dicho autor un asunto de la parte especial y no de la parte general. Por esto para sancionar la omisión impropia se debía agregar en la parte especial del Código Penal un mandato de garante junto a cada prohibición. En el mismo sentido se expresa en la doctrina chilena CURY URZÚA, Enrique, Derecho penal. Parte general, $8^{\mathrm{a}}$ ed., Santiago de Chile: ediciones Universidad Católica de Chile, 2005, p. 680.

${ }^{2}$ PECES-BARBA, Gregorio, "Los deberes fundamentales", Doxa no 4 (1987), p. 336. La cursiva es mía.

${ }^{3}$ Recientemente MAÑALICH, Juan Pablo, Norma, causalidad y acción, Madrid-Barcelona-Buenos AiresSao Paulo: Marcial Pons, 2014, pp. 18 y 19.

${ }^{4}$ JELTSCH, Alicia, Doctrina de los delitos de omisión, (Memoria de Grado), Universidad de Chile, 1968, p. 17; CURY URZÚA, Derecho, cit. nota ${ }^{\circ}$ 1, p. 677.

${ }^{5}$ GÜNTHER, Klaus, "De la vulneración de un derecho a la infracción de un deber. ¿Un "cambio de paradigma" en el derecho penal?", Trad. SILVA, Jesús-María, en: Área de Derecho Penal Universidad Pompeu Fabra, La insostenible situación del derecho penal, Granada: Comares, 2000, pp. 489-507, p. 505; DOPICO GÓMEZ-ALLER, Jacobo, Omisión e injerencia en derecho penal, Valencia: Tirant lo Blanch, 2006, p. 753; Roxin habla del "deber general" que le incumbe a todo ciudadano frente a los demás y de deberes especiales extra penales accesibles a determinados sujetos, ROXIN, Claus, Autoría y dominio del hecho, $7^{\mathrm{a}}$ ed., Trad. CUELLO, Joaquín/SERRANO, José Luis, Madrid-Barcelona: Marcial Pons, 2000, pp. 743 y ss.

${ }^{6}$ MOLINA FERNÁNDEZ, Fernando, Antijuridicidad penal y sistema del delito, Barcelona: J.M. Bosch, 2001, p. 564.
} 
un deber de no dañar a otro (deber negativo) o, por otro, uno de no colaborar en la mejora un ámbito de organización ajeno (deber positivo) ${ }^{7}$.

En relación a la última idea, esta distinción entre deberes negativos y positivos y su introducción al derecho penal se debe a Günther Jakobs. Este autor alemán ha sentado las bases de una propuesta de la responsabilidad penal bajo la distinción entre infracción de deberes negativos e infracción de deberes positivos con extraordinarias consecuencias para la dogmática penal ${ }^{8}$.

En términos generales es correcto señalar que cuando una persona tiene impuesto un determinado comportamiento por una norma jurídica entonces esa persona tiene un deber de comportarse como exige la norma ${ }^{9}$. Pero desde una perspectiva normativa de la responsabilidad penal el fundamento de dicho deber viene dado por la existencia (y vulneración) de deberes negativos y deberes positivos ${ }^{10}$. En el presente trabajo se sigue un modelo con base en esta última distinción distinguiendo los casos de infracción de un deber negativo (que en principio pareciera dirigido sólo a abstenciones) por acción y por omisión $^{11}$.

Primero que todo debe señalarse que los deberes negativos y los positivos se configuran como dos instituciones fundamentales que constituyen la estructura en la cual es posible fundamentar la responsabilidad penal de la persona. Por un lado, se encuentra la institución negativa (deberes negativos) cuyo fundamento proviene del principio iusfilosófico neminen laedere $y$, por otro, la institución positiva (deberes positivos) que se sustentan en la responsabilidad institucional y en la solidaridad para el caso de la omisión de socorro ${ }^{12}$.

\footnotetext{
${ }^{7}$ JAKOBS, Günther, "Recht und Gut. Versuch einer strafrechtlichen Begriffsbildung”, en: FREUND, Georg; MURMANN, Uwe; BLOY, René; PERRON, Walter (Eds.), Grundlagen und Dogmatik des gesamten Strafrechtssystem. FS für Wolfgang Frisch zum 70. Geburtstag, Berlín: Duncker \& Humblot, 2013, pp. 81-93, 82 y ss.

${ }^{8}$ JAKOBS, Günther, System der strafrechtlichen Zurechnung, Frankfurt am Main: Vittorio Klostermann, 2012, pp. 83 y ss.; EL MISMO, "Recht und Gut", cit. nota n 7, p. 82; EL MISMO, Dogmática del derecho penal y la configuración normativa de la sociedad, Trad. SÁNCHEZ-VERA, Javier, Madrid: Civitas, 2004, pp. 99 y ss.; EL MISMO, Derecho penal. Parte general: Fundamentos y teoría de la imputación, $2^{\mathrm{a}}$ ed., Trad. CUELLO, Joaquín/ SERRANO, José Luis, Madrid: Marcial Pons, 1997, pp. 1022 y ss. Siguiendo la misma distinción PAWLIK, Michael, Das Unrecht des Bürgers, Tübingen: Mohr Siebeck, 2012, pp. 175 y ss.; EL MISMO, "El funcionario policial como garante de impedir delitos", Trad. BACIGALUPO, Enrique et al. en: PAWLIK, Michael, La libertad institucionalizada. Estudios de filosofía jurídica y derecho penal, MadridBarcelona-Buenos Aires: Marcial Pons, 2010, pp. 197 y ss.; SÁNCHEZ-VERA GÓMEZ-TRELLES, Javier, Delito de infracción de deber y participación delictiva, Madrid-Barcelona: Marcial Pons, 2002, pp. 83 y ss.; REQUENA JULIANI, Jaime, Intercambiabilidad de acción y omisión en los delitos de dominio: Posición de garante e imputación objetiva, Madrid: Dykinson, 2010, pp. 251 y ss.; PERDOMO TORRES, Jorge Fernando, Posición de garante en virtud de confianza legítima especial, Bogotá: Universidad Externado de Colombia, 2008, pp. 109 y ss. entre otros.

${ }^{9}$ WEINBERGER, Ota, Norm und Institution: Eine Einführung in die Theorie des Rechts, Wien: Manzsche Verlag, 1988, p. 97.

${ }^{10}$ JAKOBS, "Recht und Gut", cit. nota $\mathrm{n}^{\circ} 7$, pp. 82 y ss.

${ }^{11}$ La configuración de los deberes positivos en derecho penal serán abordados en un trabajo de próxima publicación.

${ }^{12}$ En un sentido similar SILVA SÁNCHEZ, Jesús María, El delito de omisión: Concepto y sistema, $2^{\mathrm{a}}$ ed., Buenos Aires-Montevideo: B de F, 2003, p. 478; ROBLES PLANAS, Ricardo, "Deberes negativos y positivos en derecho penal", InDret $\mathrm{N}^{\circ} 4$ (2013), p. 5.
} 
NAVAS, Iván. “Acción y omisión en la infracción de deberes negativos en derecho penal".

Bajo esta construcción de la responsabilidad penal lo relevante para la determinación de la responsabilidad del autor no lo constituye la forma de la norma, esto es, si ella viene establecida bajo el binomio prohibición/mandato. Por el contrario, desde este punto de vista de los deberes, lo relevante será si la norma descansa en alguna de las instituciones negativa o positiva. De acuerdo con esto, es en consideración a esta distinción entre deberes negativos y deberes positivos cómo se deben de interpretar los distintos tipos de la parte especial del Código Penal ${ }^{13}$.

\section{Responsabilidad por infracción de deberes negativos.}

\subsection{La infracción del deber negativo por acción.}

En toda persona recae un deber negativo cuyo contenido genérico reza no dañar a otro. Puesto en contexto, la responsabilidad en virtud de la vulneración del deber negativo surge por ampliación del propio ámbito de organización a costa de otro ${ }^{14}$. Se trata en otras palabras de la responsabilidad por organización. Así, el cumplimiento del deber negativo consiste en no ampliar la propia libertad de manera no permitida hasta allí donde alcanza la libertad de otro. Evidentemente que para ello se ha de partir de la base de que toda persona configura libremente un espacio de libertad que le ha sido reconocido por el Derecho para su libre desarrollo.

Debido al otorgamiento de dicha libertad, la configuración de ésta le compete exclusivamente al propio individuo. La persona se convierte así en la única competente de la configuración de su propia libertad y al mismo tiempo en la responsable del uso permitido de ella. Por ello, la administración defectuosa de ese ámbito de organización o de esa libertad la hace responsable de aquellos daños que les ocasione a terceras personas ${ }^{15}$.

Así, libertad y responsabilidad configuran un sinalagma que reza: libertad de comportamiento para la persona / responsabilidad por las consecuencias del uso de esa libertad. Bajo tal fórmula, el deber negativo es aquel que se tiene frente a los demás en virtud del estatus general y mínimo que es exigible a toda persona en los contactos con terceros y que Hegel lo expresaba así en su célebre $§ 36$ : “sé persona y respeta a los demás como persona" ". Ello se puede traducir para el Derecho penal que aquella persona que sólo porta deberes negativos no sólo tiene el deber de no atribuirse la organización que le compete a otro, sino que también tiene el deber de revertir la atribución si ella ya ha tenido lugar ${ }^{17}$. Esta última idea que se conoce como "deber de salvamento" queda manifestado al

\footnotetext{
${ }^{13}$ En el mismo sentido SÁNCHEZ-VERA GÓMEZ TRELLES, Delito de infracción de deber, cit. nota $\mathrm{n}^{\circ}$ 8, p. 121; PERDOMO TORRES, Posición de garante, cit. nota $\mathrm{n}^{\circ}$ 8, p. 282.

${ }^{14}$ JAKOBS, Günther, System der strafrechtlichen, cit. nota no 8, pp. 83 y ss.; EL MISMO, Derecho penal, cit. nota $\mathrm{n}^{\mathrm{O}} 8$, p. 258.

${ }^{15}$ PIÑA ROCHEFORT, Juan Ignacio, Derecho penal: Fundamentos de la responsabilidad, Chile: Legal Publishing, 2010, p. 141.

${ }^{16}$ HEGEL, Georg Wilhelm Friedrich, Principios de la filosofía del Derecho, o Derecho natural y ciencia política, Trad. VERMAL, Juan Luis, Barcelona: editorial Edhasa, 1998, (§36) p. 103.

${ }^{17}$ JAKOBS, Günther, "Consumación material en los delitos de lesión contra la persona. Al mismo tiempo, una contribución a la generalización de la parte especial", Trad. CARDENAL, Sergi, RECPC, 04-13 (2002), p. 8 .
} 
observar la figura del desistimiento. En el desistimiento y a pesar de que se trata de una acción positiva que debe realizar el sujeto (desistirse), el fundamento de la sanción por la no realización de esa acción positiva de desistimiento es la lesión del deber negativo que lesiona a otro: la infracción del deber de salvamento como integrante del deber negativo. Por otro lado, en el estatus general que le compete a toda persona sólo se espera de la persona que no dañe a los demás, pues el deber negativo no genera una pretensión de que dicha persona contribuya al bienestar de otra.

En resumen, bajo un estatus general toda persona debe mantener su ámbito de organización bajo una configuración inocua para terceros, debe -en otras palabras- procurar que no se genere un output dañino o lesivo para terceros, ya sea no motivándose -siguiendo una prohibición- a una configuración que pueda provocar tal situación de peligro o eliminando mediante medidas apropiadas una configuración de su libertad peligrosa para los demás si es que dicha situación ya ha aparecido o configurado -siguiendo un mandato- ${ }^{18}$. Como consecuencia de estas premisas, parece ser que la tradicional distinción entre acción y omisión se convierte en una cuestión de menor importancia, pues lo fundamental bajo dicho planteamiento, es no dañar al otro. El cómo se organice una persona frente al deber de no dañar (si organiza por acción o por omisión), es algo en principio irrelevante para el fundamento de la responsabilidad basada en la infracción de un deber negativo.

Ahora bien, el ejercicio de la libertad jurídica garantizada se consigue configurando la propia esfera de tal modo que de ella no se desprendan riesgos que excedan del nivel permitido, ya sea evitando (prohibición) como asegurando (mandato) la propia esfera de libertad de manera inocua para los demás. En la competencia por la organización, esto es, en la responsabilidad por infracción de deberes negativos, de lo que se trata es de cumplir con el deber mínimo que recae en toda persona y que consiste en velar por que su esfera de organización no resulte dañina para terceros: quien organiza su ámbito de actuación debe cuidar que al hacerlo no produzca daño a otras personas ${ }^{19}$.

De acuerdo a lo anterior el primer fundamento de la responsabilidad es la lesión de estos límites generales de la libertad respecto de la configuración exterior del mundo ${ }^{20}$, pues cuando un ámbito de organización lesiona a otro se vulnera el espacio de libertad otorgado. En este sentido, el fundamento normativo de la responsabilidad penal viene más bien dado no por la lesión de un buen jurídico, sino por la organización defectuosa de la libertad jurídica que implica infracción del deber negativo.

Ahora bien, al autor de un delito se le imputa el ampliar su ámbito de organización a costa de otras personas, porque se arroga un ámbito de organización ajeno de manera no permitida $^{21}$. Cabe aclarar que un ámbito o esfera de organización de una persona va más

\footnotetext{
${ }^{18}$ Véase JAKOBS, Günther, La imputación penal de la acción y la omisión, Trad. SÁNCHEZ-VERA, Javier, Bogotá: Universidad Externado de Colombia, 1996, pp. 33 y 34.

${ }^{19}$ LÓPEZ BARJA DE QUIROGA, Jacobo, Tratado de derecho penal: Parte general, Madrid: Civitas, 2010, p. 798.

${ }^{20}$ JAKOBS, Günther, La competencia por organización en el delito omisivo, Trad. PEÑARANDA, Enrique, Bogotá: Universidad Externado de Colombia, 1994, p. 10.

${ }^{21}$ La determinación de lo permitido vendrá establecido por la aplicación de la teoría de la imputación objetiva del comportamiento y del resultado.
} 
NAVAS, Iván. “Acción y omisión en la infracción de deberes negativos en derecho penal".

allá de su cuerpo entendido como unidad psicofísica. Comprende también la administración de bienes y derechos que le son concedidos con exclusión de los demás, por ejemplo uso de un terreno, un automóvil, objetos para su disfrute, maquinaria etc. Así, una persona puede configurar su mundo no sólo con un movimiento corporal de su aparato psicofísico (no obstante ello sucederá en la mayoría de supuestos, por ejemplo al matar a otro, al sustraer cosa mueble ajena, al agredir sexualmente a otro, etc.), sino que también a través de innumerables posibilidades siempre que él sea el competente para su configuración. En definitiva, los círculos de organización de las personas se definen como unidades separables y ninguno de los círculos debe convertirse en la razón del empeoramiento de otro círculo ${ }^{22}$.

\subsection{La infracción del deber negativo por omisión.}

Feuerbach sostenía que los delitos omisivos sólo eran cometidos cuando no se exteriorizaba la actividad de una persona a la que tenía derecho un tercero ${ }^{23}$. Dado que, para este autor, la obligación originaria de todo ciudadano era la abstención de aquellas acciones que prohíbe la ley, la mayoría de los delitos se configuraban como acciones que infringían las prohibiciones jurídicas. De este modo, la obligación de "hacer algo" en favor de otro resultaba excepcional en el planteamiento de Feuerbach, pues según él la obligación originaria sólo corresponde a abstenciones. Por ello, para Feuerbach el delito omisivo debe presuponer un fundamento jurídico especial que se derivaba únicamente de la ley o del contrato. Sin el fundamento jurídico especial emanado de alguna de estas dos fuentes no podía tener lugar un delito de omisión ${ }^{24}$. Bajo dicho planteamiento queda claro que el deber de actuar sólo existe si la ley o un contrato así lo establecían previamente.

Ahora bien, las ideas de Feuerbach dieron origen a la denominada teoría formal del deber jurídico, la cual ha sido doctrina dominante en buena parte de la literatura nacional y comparada durante bastante tiempo sin que dicha situación se haya advertido lo suficiente.

El pensamiento y las ideas de Feuerbach tuvieron gran recepción en buena parte de la doctrina penal de corte continental y sus planteamientos se pueden observar también en los principales autores de la doctrina chilena que podría denominarse como "dominante". Así, puede desprenderse en cierta medida el pensamiento de Feuerbach de las obras de Etcheberry, Cury Urzúa, Garrido Montt entre otros ${ }^{25}$.

\footnotetext{
${ }^{22}$ JAKOBS, Günther, Injerencia y dominio del hecho, Trad. CANCIO, Manuel, Bogotá: Universidad Externado de Colombia, 2001, p. 11.

${ }^{23}$ FEUERBACH, Paul Anselm Johann von, Lehrbuch des gemeinen in Deutschland gültigen peinlichen Rechts, $2^{\mathrm{a}}$ reimpresión de la $14^{\mathrm{a}}$ ed. de Giessen de 1847, Deutschland: Scientia Verlag Aalen, 1986, (§ 24) p. 50 .

${ }^{24}$ FEUERBACH, Lehrbuch des gemeinen, cit. nota ${ }^{\circ} 22$, (§ 24) p. 50: "Debido a que la obligación originaria del ciudadano se refiere sólo a abstenciones, concurre un delito de omisión siempre que presuponga una base jurídica especial (Ley o contrato), a través de la cual cuales se fundamenta la responsabilidad de la comisión. Sin estos, no existe delito por omisión".

${ }^{25}$ Véase CURY URZÚA, Derecho, cit. nota no 1, p. 677; GARRIDO MONTT, Mario, Derecho penal: Parte general, t. II, Santiago de Chile: Editorial Jurídica de Chile, 1997, p. 183.
} 
Polít. crim. Vol. 10, No 20 (Diciembre 2015), Art. 8, pp. 678-693.

[http://www.politicacriminal.cl/Vol_10/n_20/Vol10N20A8.pdf]

En efecto, ejemplo de ello es el concepto que de omisión de Etcheberry para quien la omisión es "la no ejecución de la acción mandada por la ley"26. Como se observa, para este último autor únicamente tiene relevancia penal la omisión de aquella acción que exige la ley. Esta afirmación se ve ratificada en el momento en que este mismo autor rechaza la injerencia como fuente de la posición de garante, quedando por consecuencia en su planteamiento como fuentes de la posición de garantía únicamente la ley, el contrato y la profesión de riesgo ${ }^{27}$.

Por otra parte, si bien Garrido Montt sostiene que lo importante de atender a un criterio normativo para la imputación del resultado en comisión por omisión, presenta a la causalidad hipotética como el criterio normativo a utilizar para determinar si la acción no realizada hubiera evitado o disminuido la producción del resultado ${ }^{28}$. Y ello sólo para afirmar ni siquiera la certeza sino la posibilidad de la evitación. En este sentido, es difícil aceptar que una probabilidad opera como un criterio normativo en los casos de las omisiones impropias. Más bien tal factor no deja de ser pura casualidad. En efecto, si se está barajando criterios que provienen "del mundo de las posibilidades hipotéticas" para imputar un resultado a una omisión, difícilmente ello otorgará una seguridad que siempre estará sujeta a críticas.

La comprensión de que las fuentes de la posición de garante deriven de la ley y del contrato ha sido duramente criticada por la doctrina moderna. Tanto es así que debe afirmarse que actualmente estas posiciones del deber jurídico han sido abandonadas casi por completo ${ }^{29}$. En el fondo estas posturas que derivan la posición de garante de la ley o del contrato constituyen una postura formalista de comisión por omisión sin fundamentación material del deber de garante. O más bien sin un fundamento material de por qué la omisión equivale a la acción. En un comienzo, debido a la influencia de Feuerbach y también de pensadores como Kant, la preocupación de las tesis formalistas consistía en que determinados deberes éticos o sociales de actuar llegaran a restringir la libertad de actuación de las personas ${ }^{30}$.

En cierta medida existía temor de que omisiones con un evidente y natural contenido ético o moral pudieran ser sancionadas jurídicamente, por lo cual se miraba con recelo cualquier intento de sancionar omisiones que no tuviesen un fundamento en la ley o en un contrato. No obstante, este temor es en buena parte infundado. En efecto, pues siempre se trata de omisiones graves que muestren una identidad material a una acción emanada del ejercicio de la propia libertad y no un simple no hacer que pudiese conectarse hipotéticamente con la

\footnotetext{
${ }^{26}$ ETCHEBERRY, Alfredo, Derecho penal. Parte general, $3^{a}$ ed., Chile: Editorial Jurídica de Chile, 1998, p. 200.

${ }^{27}$ Cfr. ETCHEBERRY, Derecho penal, cit. nota $\mathrm{n}^{\circ} 25$, pp. 205 y 206.

${ }^{28}$ Cfr. GARRIDO MONTT, Derecho penal, cit. nota $\mathrm{n}^{\circ} 24$, p. 190.

${ }^{29}$ Véase KAUFMANN, Dogmática, cit. nota ${ }^{\circ}$ 1, pp. 254 y ss.; SCHÜNEMANN, Bernd, Fundamentos y límites de los delitos de omisión impropia, Trad. CUELLO, Joaquín/SERRANO, José Luis, Barcelona: Marcial Pons, 2009, pp. 265 y ss.; POLITOFF, Sergio; MATUS, Jean-Pierre; RAMÍREZ, María Cecilia, Lecciones de derecho penal. Parte general, $2^{\mathrm{a}}$ ed., Chile: Editorial Jurídica de Chile, 2004, p. 204.

${ }^{30}$ Véase al respecto SEELMANN, Kurt, “EExisten deberes de solidaridad en el derecho penal?”, en: SEELMANN, Kurt, Estudios de filosofía del derecho y derecho penal, Madrid-Barcelona-Buenos Aires-Sao Paulo: Marcial Pons, 2013, pp. 76 y ss.
} 
NAVAS, Iván. “Acción y omisión en la infracción de deberes negativos en derecho penal".

causación de un resultado no imputable a la conducta omisiva de quien pudo pero no hizo algo.

Ahora bien, la preocupación de las tesis formalistas se soluciona además sin necesidad de reducir en exceso las fuentes de la posición de garante recurriendo únicamente a deberes establecidos en la ley o en un contrato, sino que se puede restringir al recurrir a estructuras de imputación normativo-materiales que estén referidas la infracción de deberes negativos por omisión mediante la asunción previa del dominio del riesgo típico en la propia esfera de organización sumada a la posterior vulneración del compromiso adquirido. En el fondo, el temor que inspiraba las restricciones de las teorías formales del deber jurídico se disipa al recurrir siempre como criterio de identidad al ejercicio de la misma libertad que se intentaba defender por parte de autores como Feuerbach y Kant.

Efectivamente, en muchos ámbitos de la vida las personas se encuentran sujetas a deberes especiales (como los que señalaba Feuerbach) dirigidos a la evitación de ciertos resultados, pero sería absurdo intentar derivar de la infracción de cualquiera de estos deberes la responsabilidad penal de un delito de resultado en comisión por omisión ${ }^{31}$. De hecho, la infracción del deber de actuar está presente en el delito de omisión de socorro del art. 494.11 del Código Penal (en adelante, CP) y aun así su vulneración no basta para hacer responsable al omitente en comisión por omisión ${ }^{32}$. Por otra parte, el recurso a normas extrapenales como fundamento legal por parte de las tesis formalistas es erróneo por el hecho de que tales normas que dependen de otras ramas del ordenamiento jurídico no tienen por finalidad una estabilización normativa o una protección de un bien jurídico penal a través de la imposición de una pena, sino que regulan únicamente determinadas consecuencias del concreto ámbito de aplicación; esto es, del derecho civil, del derecho administrativo, del derecho tributario, etc.

Por otro lado se ha criticado que el hecho de recurrir a una infracción de una norma extra penal como fuente de la posición de garante genera la irresoluble antinomia normativa de una doble antijuridicidad, es decir, una antijuridicidad extra penal y una penal ${ }^{33}$. De esta forma el delito de omisión exigiría un requisito más que el delito de acción. Tal requisito adicional para la omisión sería la contradicción de una norma extra penal. En tal sentido debe afirmarse que no existiría identidad entre el delito omisión y el delito comisivo ya que para la responsabilidad penal por delito omisión sería necesario contar un requisito adicional a los establecidos por la propia teoría del delito.

En resumen, la tesis formalista de la responsabilidad por omisión representa una tesis sistemáticamente insuficiente por el hecho de que la posición de garante del omitente dependa exclusivamente si el deber está o no formulado por la ley o el contrato. Ello tiene como consecuencia una solución estrecha en algunos casos y en otros, una solución que

\footnotetext{
${ }^{31}$ DOPICO GÓMEZ-ALLER, Omisión, cit. nota nº 5, p. 134.

${ }^{32}$ La omisión de socorro es en la inmensa mayoría de ordenamientos jurídicos un delito aunque en nuestro anacrónico Código Penal lo tipifique como una falta con pena de multa.

${ }^{33}$ Véase las críticas en WELP, Jürgen, Vorangegangenes Tun als Grundlage einer Handlungsäquivalenz der Unterlassung, Berlin: Duncker \& Humblot, 1968, pp. 63 y ss.
} 
Polít. crim. Vol. 10, No 20 (Diciembre 2015), Art. 8, pp. 678-693.

[http://www.politicacriminal.cl/Vol_10/n_20/Vol10N20A8.pdf]

desbordaría los límites de la responsabilidad ${ }^{34}$. En efecto, piénsese por ejemplo en el caso de la niñera en el cual difícilmente podría negarse la posición de garante a pesar de que posteriormente al hecho se constatara la ineficacia del contrato por el cual se obligaba a cuidar a un menor en ausencia de los padres de éste. La dependencia extra penal es excesiva si atiende en especial a las repercusiones penales que se le da a una infracción extra penal. Esto es, la afirmación de que a través de la vulneración de un mandato extra penal de cualquier otra rama del ordenamiento jurídico, es equivalente a la realización en comisión activa de un hecho penalmente típico.

Debido a la influencia del pensamiento de Feuerbach no es extraño que se encuentren opiniones que señalen que "todos los crímenes o simples delitos contra las personas están concebidos como delitos comisivos" 35 , dejando ver a contrario sensu a la imposibilidad de aceptar su modalidad omisiva impropia. Sin embargo, según Cury, la norma del art. 492 del CP salva la cuestión de la tipicidad de la omisión impropia frente a los delitos contra las personas, pues en tal norma se sanciona la omisión que, de mediar malicia, constituiría un crimen o un simple delito contra las personas ${ }^{36}$. Ahora bien, la conclusión a la que se llega con tal planteamiento es que todos aquellos delitos que no atenten contra las personas no podrían ser realizados mediante comisión por omisión. Conclusión que no puede ser aceptada, pues ello tendría como consecuencia que, por ejemplo, ningún delito que guarde relación con el derecho penal económico podría ser realizado por omisión.

La similitud de algunos autores chilenos con la postura de Feuerbach es manifiesta. Seguramente ello se debe a que tales autores parten de la base de que los tipos penales describen procesos de causación activos en un sentido puramente físico naturalístico, por lo que la punibilidad de la omisión sería en tal caso excepcional. En efecto, más que una descripción de procesos causales físicos que pudiera afirmarse en la descripción de los tipos penales, ese mayor impacto social que parece tener la realización de una acción por sobre una omisión sea una forma de observación por parte del hombre medio. Así no es de extrañar que en ocasiones se afirme por nuestra más destacable doctrina que existe una sensación generalizada de que "es más injusta la conducta del que actúa que la del que omite". ${ }^{37}$

La cuestión es que efectivamente dichas valoraciones sociales acaban influyendo en las estructuras de imputación jurídico-penales configurando una especial relevancia normativa de la causalidad. Sin embargo, desde una óptica normativa la causalidad no representa el único factor a tener en consideración en la discusión de la comisión y la omisión, y no se debe caer en valoraciones a priori a la hora de valorar conductas humanas como la acción y la omisión, pues ambas clases de comportamiento pueden poseer idéntico desvalor para el derecho penal.

\footnotetext{
${ }^{34}$ KÖHLER, Michael, Strafrecht Allgemeiner Teil, 7ª ed., Berlin-Heidelberg-New York: Springer, 1997, pp. 211 y 212.

${ }^{35}$ CURY URZÚA, Derecho, cit. nota $n^{\circ} 1$, p. 680.

${ }^{36}$ CURY URZÚA, Derecho, cit. nota $n^{\circ} 1$, p. 680.

${ }^{37}$ CURY URZÚA, Derecho, cit. nota ${ }^{\circ} 1$, p. 686.
} 
NAVAS, Iván. “Acción y omisión en la infracción de deberes negativos en derecho penal".

Volviendo a la estructura de los deberes de la que parte este trabajo, el hecho que se trate de un deber negativo no debe dar lugar a que su infracción sólo se lleva a cabo por acciones. Si bien la comisión activa será la forma más común de lesionar el deber negativo, éste también se puede infringir a través de una omisión. Efectivamente, de acuerdo al planteamiento que aquí se defiende, el deber negativo se lesiona por omisión a través de la estructura de la comisión por omisión.

No obstante, el hecho de que en la comisión por omisión se trate de un no hacer algo y que del hecho resulte un beneficio de una esfera ajena, el fundamento normativo de la responsabilidad de la comisión por omisión es la vulneración del deber negativo de no dañar, esto es, responsabilidad por la organización. Ello se debe a que la comisión por omisión es una forma más de organizar la propia esfera junto a la comisión activa ${ }^{38}$. En otras palabras, la comisión por omisión es una variante de responsabilidad por organización de la propia esfera de competencia. De acuerdo a lo señalado cabe afirmar que la comisión por omisión es también una forma de infracción de un deber negativo por el ejercicio no permitido de la libertad. Ahora bien, la posición de garantía no viene establecida por la existencia y posterior vulneración de un deber extra penal o de la existencia de un deber de actuar establecido en un contrato. De hecho cabe sostener como acertadamente ha señalado Mañalich que la denominada posición de garantía nos dice quién puede ser autor de un delito de omisión impropia, pero todavía no nos dice por qué $e^{39}$.

De acuerdo a un planteamiento restrictivo de la comisión por omisión ${ }^{40}$, la identidad normativa de la comisión por omisión con la comisión activa se encuentra en el acto previo de asunción del compromiso de contención de riesgos y posterior vulneración de tal compromiso como expresión del ejercicio de la libertad. Piénsese como ejemplo el caso de los trapecistas de circo en que sin existir contrato, ley, ni injerencia previa uno de ellos no extiende los brazos cuando el otro salta al vacío esperando que su compañero lo tome de las manos para evitar la caída. En casos como este no hace falta recurrir a una norma expresa de identidad entre la omisión y la acción (al estilo de la cláusula general del parágrafo 13 alemán o del art. 11 del Código penal español), pues la adscripción de responsabilidad al trapecista resulta bastante evidente, primero si se parte de la comprensión de que los tipos penales no describen meros procesos causales, sino que adscriben responsabilidad y segundo por la existencia de una asunción de un compromiso de evitación de que el riesgo se realice en el resultado como criterio de identidad material entre la omisión y la acción para los delitos de resultado ${ }^{41}$. En el ejemplo propuesto, es manifiesto que quien organiza la muerte del sujeto que cae al vacío es el trapecista que no ejecuta la acción de sujetar a su compañero habiendo asumido incluso tácitamente el compromiso de hacerlo. Como no

\footnotetext{
${ }^{38}$ Véase SILVA SÁNCHEZ, El delito de omisión, cit. nota n ${ }^{\circ}$ 11, p. 478; EL MISMO, "Entre la omisión de socorro y la comisión por omisión. Las estructuras de los arts. 195.3 y 196 del código penal”, en: AA.VV, Problemas específicos de la aplicación del código penal, Madrid: CGPJ, 1999, pp.153-172, pp. 153 y ss.

${ }^{39}$ MAÑALICH, Juan Pablo, “Omisión del garante e intervención delictiva. Una reconstrucción desde la teoría de las normas", Revista de Derecho. Universidad Católica del Norte, vol. 21, no 2 (2014), p. 245.

${ }^{40}$ Véase SILVA SÁNCHEZ, El delito de omisión, cit. nota no 11, pp. 471 y ss., EL MISMO, "Artículo 11", en: COBO DEL ROSAL, Manuel (Dir.), Comentarios al código penal, t. I, Madrid: Edersa, 1999, pp.441488 , p. 464.

${ }^{41}$ La asunción como criterio de identidad no tiene por qué ser expresa, puede ser tácita y desprenderse del contexto social de interacción entre dos o más sujetos en un momento determinado.
} 
existe un deber extra penal que señale que "todo trapecista debe abrir sus brazos cuando su compañero salte al vacío", se hace necesario rechazar el planteamiento formalista y recurrir a una propuesta material de identidad entre la omisión y la acción mediante el fundamento de la asunción.

Por ello, incluso la cláusula general al estilo del art. 11 del Código penal español o 13 del parágrafo del StGB que establece los requisitos para equiparar la omisión a la acción no juegan en realidad un rol fundamental y podría sin mayores problemas prescindirse de ella en una futura regulación del $\mathrm{CP}$ chileno. Cabe recordar que la ausencia de esta cláusula general no invalida las sanciones en comisión por omisión establecidas previamente a la tipificación de una cláusula general. Incluso en aquellos países que aún no cuentan con una cláusula general, nada imposibilita las sanciones a título de comisión por omisión. Sin embargo, su establecimiento obedece seguramente a ciertas necesidades históricas basadas en nuestro país bajo una tradición legalista y formalista y para cumplir con un aparente "respeto" del principio de legalidad que sería vulnerado si no existiese tal cláusula general.

\subsection{La concreción de los deberes negativos en la parte especial del derecho penal.}

La mayoría de figuras delictivas que se encuentran en la parte especial, constituyen infracciones del deber negativo de no dañar. El homicidio, la estafa, robo, hurto, etc., son arrogaciones de la libertad de una esfera jurídica. Cada uno de los tipos penales de la parte especial corresponde a una personificación de la lesión de libertad de una esfera de organización ajena $^{42}$. Ahora bien, algunos delitos producen más o menos confusión en cuanto al deber que fundamenta su imputación. Así por ejemplo, Piña Rochefort ha dicho que el abandono de menores contiene un deber de solidaridad del sujeto que abandona a un menor $^{43}$. Sin embargo, tal afirmación debe ser rechazada. Desde la perspectiva que aquí sostengo, quien abandona a un menor no responde penalmente por un delito de infracción de deber, pues no ocupa una posición institucional basada en deberes positivos, sino que responderá por haber "organizado" algo no permitido: el abandono.

En efecto, la posición jurídica del autor del delito de abandono de un menor debe distinguirse entre aquel sujeto que ninguna relación tiene con el menor (art. 346 del CP) y quien ostenta el cuidado de él. En el primer caso, el deber de no abandonar a un menor se dirige a cualquier persona. Se trata en dicho caso de un deber positivo general, o de solidaridad mínima. En el segundo, esto es (art. 347 del CP) se trata de aquella situación de quien abandona a un menor teniéndolo bajo su cuidado. Lo que se produce aquí es que quien ha asumido el cuidado de ese menor vulnera ese compromiso, infringiendo un deber negativo que viene configurado por la asunción previa de la protección del menor. Debido a la asunción de una esfera ajena (el menor), detrás del abandono no hay una infracción de un deber de solidaridad, sino una infracción a un deber negativo de no dañar a otro, pues cuando asumo el cuidado de algo no surgen deberes de solidaridad con esa esfera ajena, sino deberes de no dañar.

\footnotetext{
${ }^{42}$ Véase PAWLIK, Das Unrecht, cit. nota $\mathrm{n}^{\circ}$ 8, p. 157.

${ }^{43}$ PIÑA ROCHEFORT, Derecho penal, cit. nota $n^{\circ} 14$, p. 149.
} 
NAVAS, Iván. “Acción y omisión en la infracción de deberes negativos en derecho penal".

Ahora bien, no solo en los delitos contra las personas tiene aplicación la distinción entre deberes negativos y positivos. Ello también es aplicable a los delitos económicos. Así por ejemplo, está el caso de los delitos de insolvencia ${ }^{44}$. Se ha señalado por alguna parte de la doctrina que el deudor (autor de un delitos de insolvencia) tiene un deber positivo respecto a su acreedor cuando se encuentra en un estado de insolvencia inminente ${ }^{45}$. Hasta donde alcanzo a ver, para Feijoo Sánchez el "estatus especial" del deudor derivaría de lo que establece la Ley Concursal Española (Ley 5/2003 de 22 de julio) que en su artículo 5 prescribe el deber del deudor de solicitar el concurso de acreedores dentro de los dos meses siguientes a la fecha en que hubiera conocido o debido conocer su estado de insolvencia. En consecuencia, según observo, el deudor debería ayudar a sus acreedores solicitando el concurso voluntario para cumplir así con el principio de pago par conditio creditorum.

Sin embargo, afirmar que recae en el deudor un deber positivo es afirmar bajo el planteamiento institucional de Jakobs la existencia de una institución que vincule al deudor con el acreedor que sea de tanta importancia para la configuración social como lo es la libertad de organización, esto es, que no se puede renunciar a ella sin renunciar a la configuración social básica ${ }^{46}$. En tal sentido es bastante difícil afirmar la existencia de una institución que vincule al deudor con su acreedor. Cabe imaginarse a primera vista, que el "crédito" podría ser una institución fundamental, sin la cual no se comprendería la configuración social (y económica) actual.

No obstante, con semejante razonamiento se pueden imaginar innumerables "instituciones" fundamentales para el desarrollo social actual y no por eso puede afirmarse que contengan deberes positivos que den lugar a delitos conocidos como delitos de infracción de deber. Así por ejemplo, el consumo de bienes y servicios es una forma de organización social sobre la cual se organiza la sociedad. Sin embargo, que los delitos contra los consumidores sean delitos que lesionen a una institución y den lugar a delitos de infracción de deber corresponde a una expansión inaceptable del concepto de institución. En mi opinión, los delitos de concurso o delitos de insolvencia tienen un fundamento normativo basado en la institución negativa de no lesionar a otro ${ }^{47}$.

Esto es, todo delito de insolvencia del deudor lesiona un deber negativo y dada la configuración propia de los delitos de concurso, ese otro es el acreedor. La responsabilidad del deudor se basa en el sinalagma libertad de organización/responsabilidad por las consecuencias. Efectivamente, el deudor es libre de organizar su patrimonio de la manera que estime conveniente. No obstante, existen límites a esa libertad que radican en no someter su patrimonio a un riesgo de insolvencia, ya que a través de ésta última genera un riesgo no permitido que ocasiona una lesión a sus acreedores ${ }^{48}$. En concreto, el deber

\footnotetext{
${ }^{44}$ Los tradicionalmente conocidos como delitos de quiebra hoy en día se conocen como delitos de insolvencia o delitos de concurso de acreedores. Ver artículo 463 y siguientes del código penal.

${ }^{45}$ FEIJOO SÁNCHEZ, Bernardo, "Imputación objetiva en el derecho penal económico y empresarial. Esbozo de una teoría general de los delitos económicos", InDret 2 (2009), p. 11.

${ }^{46}$ JAKOBS, Günther, Strafrecht. Allgemeiner Teil, $2^{\mathrm{a}}$ ed., Berlin-New York: Walter de Gruyter, 1991, nm. $1 / 8$.

${ }^{47}$ NAVAS, Iván, Insolvencias punibles. Fundamentos y límites, Madrid-Barcelona-Buenos Aires-Sao Paulo: Marcial Pons, 2015, pp. 183 y 263.

${ }^{48}$ NAVAS, Iván, Insolvencias punibles. Fundamentos y límites, cit. nota no 46, p. 275.
} 
Polít. crim. Vol. 10, № 20 (Diciembre 2015), Art. 8, pp. 678-693.

[http://www.politicacriminal.cl/Vol_10/n_20/Vol10N20A8.pdf]

negativo del deudor consiste en un deber de no lesionar fraudulentamente el patrimonio de sus acreedores defraudando las expectativas de cobro a través de la creación de una situación de insolvencia.

Lo que se ha señalado hasta ahora pone de manifiesto que del deber negativo no sólo emanan deberes de abstención o de omitir acciones lesivas, sino que también surgen deberes de ejecutar acciones apropiadas cuando se ha asumido el compromiso de la evitación del daño. Que de las prohibiciones emanen deberes de obrar no sólo lo pone de manifiesto el caso de la comisión por omisión, sino también como se señalada, lo pone de manifiesto la figura del desistimiento de la tentativa, pues en dicho caso el sujeto debe "hacer algo positivo", esto en términos causales "ejecutar una acción" que ponga fin a la tentativa. Con ello se observa que el fundamento normativo de un delito es una cuestión distinta de la forma en cómo se cumple ese deber.

En resumen, el mensaje del dictado jurídico de la norma prohibitiva puede comprenderse como "no organices tu libertad de manera no permitida", ejecutando acciones que lesionen la libertad de otra esfera de organización, u omitiendo aquellas necesarias para evitar un resultado cuando se haya asumido el compromiso de actuar.

En tal sentido, puede afirmarse incluso que no es conditio sine qua non la existencia de una cláusula general de equivalencia de la omisión a la acción para la sanción de las omisiones impropias pues la atribución de un resultado a la omisión de un sujeto que había asumido el compromiso de actuar llegado el caso, opera mediante la identidad estructural entre la omisión y la acción. Sin embargo, la tradición jurídica-penal parece sentirse más cómoda con la existencia de una norma expresa que establezca los requisitos necesarios para reafirmar la identidad de omisiones con acciones prohibitivas de un resultado. 
NAVAS, Iván. “Acción y omisión en la infracción de deberes negativos en derecho penal".

\section{BIBLIOGRAFÍA}

COUSIÑO MACIVER, Luis, Derecho penal chileno, t. I, Santiago de Chile: Editorial Jurídica de Chile, 1975.

CURY URZÚA, Enrique, Derecho penal. Parte general, $8^{\mathrm{a}}$ ed., Santiago de Chile: ediciones Universidad Católica de Chile, 2005.

DOPICO GÓMEZ-ALLER, Jacobo, Omisión e injerencia en derecho penal, Valencia: Tirant lo Blanch, 2006.

ETCHEBERRY, Alfredo, Derecho penal: Parte general, $3^{\text {a }}$ ed., Chile: Editorial Jurídica de Chile, 1998.

FEIJOO SÁNCHEZ, Bernardo, "Imputación objetiva en el derecho penal económico y empresarial. Esbozo de una teoría general de los delitos económicos”, InDret 2 (2009),

FEUERBACH, Paul Anselm Johann von, Lehrbuch des gemeinen in Deutschland gültigen peinlichen Rechts, $2^{\mathrm{a}}$ reimpresión de la $14^{\mathrm{a}}$ ed. de Giessen de 1847, Deutschland: Scientia Verlag Aalen, 1986.

GARRIDO MONTT, Mario, Derecho penal: Parte general, t. II, Santiago de Chile: Editorial Jurídica de Chile, 1997.

GÜNTHER, Klaus, "De la vulneración de un derecho a la infracción de un deber. ¿Un «cambio de paradigma» en el derecho penal?”, Trad. SILVA, Jesús-María, en: Área de Derecho Penal Universidad Pompeu Fabra, La insostenible situación del derecho penal, Granada: Comares, 2000, pp. 489-507.

HEGEL, Georg Wilhelm Friedrich, Principios de la filosofía del Derecho, o Derecho natural y ciencia política, Trad. VERMAL, Juan Luis, Barcelona: editorial Edhasa.

JAKOBS, Günther, “Consumación material en los delitos de lesión contra la persona. Al mismo tiempo, una contribución a la generalización de la parte especial”, Trad. CARDENAL, Sergi, volumen, RECPC 04-13 (2002), pp. 1-18.

, Derecho penal. Parte general: Fundamentos y teoría de la imputación, $2^{\mathrm{a}}$ ed., Trad. CUELLO, Joaquín/SERRANO, José Luis, Madrid: Marcial Pons, 1997.

, Dogmática del derecho penal y la configuración normativa de la sociedad, Trad. SÁNCHEZ-VERA, Javier, Madrid: Civitas, 2004. Injerencia y dominio del hecho: Dos estudios sobre la parte general del Derecho penal, Trad. CANCIO, Manuel, Bogotá: Universidad Externado de Colombia, 2001. La competencia por organización en el delito omisivo, Trad. PEÑARANDA, Enrique, Bogotá: Universidad Externado de Colombia, 1994.

, La imputación penal de la acción y la omisión, Trad. SÁNCHEZ-VERA, Javier, Bogotá: Universidad Externado de Colombia, 1996.

, "Recht und Gut. Versuch einer strafrechtlichen Begriffsbildung", en: FREUND, Georg; MURMANN, Uwe; BLOY, René; PERRON, Walter (Eds.), Grundlagen und Dogmatik des gesamten Strafrechtssystem. FS für Wolfgang Frisch zum 70. Geburtstag, Berlín: Duncker \& Humblot, 2013, pp. 81-93. , Strafrecht: Allgemeiner Teil, $2^{\mathrm{a}}$ ed., Berlin-New York: Walter de Gruyter, 1991.

System der strafrechtlichen Zurechnung, Frankfurt am Main: Vittorio Klostermann, 2012.

JELTSCH, Alicia, Doctrina de los delitos de omisión (Memoria de Grado), Universidad de Chile, 1968. 
Polít. crim. Vol. 10, № 20 (Diciembre 2015), Art. 8, pp. 678-693.

[http://www.politicacriminal.cl/Vol_10/n_20/Vol10N20A8.pdf]

KAUFMANN, Armin, Dogmática de los delitos de omisión, Trad. CUELLO, Joaquín/ SERRANO, José Luis, Madrid-Barcelona: Marcial Pons, 2006.

KÖHLER, Michael, Strafrecht Allgemeiner Teil, $7^{\mathrm{a}}$ ed., Berlin-Heidelberg-New York: Springer, 1997.

LÓPEZ BARJA DE QUIROGA, Jacobo, Tratado de derecho penal: Parte general, Madrid: Civitas, 2010.

MAÑALICH, Juan Pablo, Norma, causalidad y acción, Madrid-Barcelona-Buenos AiresSao Paulo: Marcial Pons, 2014.

"Omisión del garante e intervención delictiva. Una reconstrucción desde la teoría de las normas", Revista de Derecho. Universidad Católica del Norte, vol. 21, $\mathrm{n}^{\mathrm{o}} 2$ (2014), pp.225-276.

MOLINA FERNÁNDEZ, Fernando, Antijuridicidad penal y sistema del delito, Barcelona: J.M. Bosch, 2001.

NAVAS, Iván, Insolvencias punibles: Fundamentos y límites, Madrid-Barcelona-Buenos Aires-Sao Paulo: Marcial Pons, 2015.

PAWLIK, Michael, Das Unrecht des Bürgers, Tübingen: Mohr Siebeck, 2012.

"El funcionario policial como garante de impedir delitos", Trad. BACIGALUPO, Enrique et al., en: PAWLIK, Michael, La libertad institucionalizada. Estudios de filosofía jurídica y derecho penal, Madrid-Barcelona-Buenos Aires: Marcial Pons, 2010, pp. 181-205.

PECES-BARBA, Gregorio, “Los deberes fundamentales”, Doxa n 4(1987), pp. 329-341.

PERDOMO TORRES, Jorge Fernando, Posición de garante en virtud de confianza legítima especial, Bogotá: Universidad Externado de Colombia, 2008.

PIÑA ROCHEFORT, Juan Ignacio, Derecho penal: Fundamentos de la responsabilidad, Chile: Legal Publishing, 2010.

POLITOFF, Sergio; MATUS, Jean-Pierre; RAMÍREZ, María Cecilia, Lecciones de derecho penal: Parte general, $2^{\mathrm{a}}$ ed., Chile: Editorial Jurídica de Chile, 2004.

REQUENA JULIANI, Jaime, Intercambiabilidad de acción y omisión en los delitos de dominio: Posición de garante e imputación objetiva, Madrid: Dykinson, 2010.

ROBLES PLANAS, Ricardo, "Deberes negativos y positivos en derecho penal", InDret $\mathrm{N}^{\circ}$ 4 (2013).

ROXIN, Claus, Autoría y dominio del hecho, $7^{\mathrm{a}}$ ed., Trad. CUELLO, Joaquín/ SERRANO, José Luis, Madrid-Barcelona: Marcial Pons, 2000.

SÁNCHEZ-VERA GÓMEZ-TRELLES, Javier, Delito de infracción de deber y participación delictiva, Madrid-Barcelona: Marcial Pons, 2002.

SCHÜNEMANN, Bernd, Fundamentos y límites de los delitos de omisión impropia, Trad. CUELLO, Joaquín/SERRANO, José Luis, Barcelona: Marcial Pons, 2009.

, Fundamentos y límites de los delitos de omisión impropia, Trad. CUELLO, Joaquín/SERRANO, José Luis, Barcelona: Marcial Pons, 2009.

SEELMANN, Kurt, “Existen deberes de solidaridad en el derecho penal?”, Trad. en: SEELMANN, Kurt, Estudios de filosofía del derecho y derecho penal, MadridBarcelona-Buenos Aires-Sao Paulo: Marcial Pons, 2013.

SILVA SÁNCHEZ, Jesús María, El delito de omisión: Concepto y sistema, $2^{\mathrm{a}}$ ed., Buenos Aires-Montevideo: B de F, 2003.

, “Artículo 11", en: COBO DEL ROSAL, Manuel (Dir.), Comentarios al código penal, t. I, Madrid: Edersa, 1999, pp. 442-488. 
NAVAS, Iván. “Acción y omisión en la infracción de deberes negativos en derecho penal".

, "Entre la omisión de socorro y la comisión por omisión. Las estructuras de los arts. 195.3 y 196 del código penal", en: VV.AA., Problemas específicos de la aplicación del código penal, Madrid: CGPJ, 1999, pp. 153-172.

WEINBERGER, Ota, Norm und Institution: Eine Einführung in die Theorie des Rechts, Wien: Manzsche Verlag, 1988.

WELP, Jürgen, Vorangegangenes Tun als Grundlage einer Handlungsäquivalenz der Unterlassung, Berlin: Duncker \& Humblot, 1968. 